\title{
TERMINAL VALUE PROBLEMS OF IMPULSIVE INTEGRO-DIFFERENTIAL EQUATIONS IN BANACH SPACES ${ }^{1}$
}

\author{
DAJUN GUO \\ Shandong University \\ Department of Mathematics \\ Jinan 250100, PR of China
}

(Received September, 1995; Revised February, 1996)

\begin{abstract}
This paper uses cone theory and the monotone iterative technique to investigate the existence of minimal nonnegative solutions of terminal value problems for first order nonlinear impulsive integro-differential equations of mixed type in a Banach space.

Key words: Terminal Value Problem, Impulsive Integro-Differential Equation, Cone Theory, Monotone Iterative Technique.
\end{abstract}

AMS subject classifications: 45J05.

\section{Introduction}

The theory of impulsive differential equations has become an important area of investigation. Initial value problems of such equations have been discussed in detail in recent years (see [3]). In this paper, we shall use cone theory and the monotone iterative technique to investigate the existence of a minimal nonnegative solution of the terminal value problem (TVP) for a first order nonlinear impulsive integrodifferential equation of mixed type in a Banach space.

\section{Preliminaries}

Let $E$ be a real Banach space and $P$ be a cone in $E$ which defines a partial order in $E: \quad x \leq y$ if and only if $y-x \in P . \quad P$ is said to be normal if there exists a positive constant $N$ such that $\theta \leq x \leq y$ implies $\|x\| \leq N\|y\|$, where $\theta$ denotes the zero element of $E . P$ is said to be regular (or fully regular) if $x_{1} \leq x_{2} \leq \ldots \leq x_{n} \leq \ldots \leq y$ (or $x_{1} \leq x_{2} \leq \ldots \leq x_{n} \leq \ldots$ with $\sup _{n}\left\|x_{n}\right\|<\infty$ ) implies $\left\|x_{n}-x\right\| \rightarrow 0$ as $n \rightarrow \infty$ for some $x \in E$. The full regularity of $P$ implies the regularity of $P$, and the regularity of $P$ implies the normality of $P$ (see [2], Theorem 1.2.1). Moreover, if $E$ is weakly complete (in particular, reflexive), then the normality of $P$ implies the regularity of

\footnotetext{
${ }^{1}$ Research supported by NNSF-China and SECDF-China. 
$P$ (see [1], Theorem 2.2).

Consider the TVP in $E$ :

$$
\left\{\begin{array}{cc}
x^{\prime}=f(t, x, T x, S x), & t \in J, t \neq t_{m}, \\
\left.\Delta x\right|_{t=t_{m}}=I_{m}\left(x\left(t_{m}\right)\right), & (m=1,2,3, \ldots), \\
x(\infty)=x^{*} &
\end{array}\right.
$$

where $J=[0, \infty), \quad f \in C(J \times P \times P \times P,-P), \quad 0<t_{1}<\ldots<t_{m}<\ldots, \quad t_{m} \rightarrow \infty$ and $m \rightarrow \infty, I_{m} \in C(P,-P)(m=1,2,3, \ldots), x^{*} \in P, x(\infty)=\lim _{t \rightarrow \infty} x(t)$, and

$$
(T x)(t)=\int_{0}^{t} k(t, s) x(s) d s,(S x)(t)=\int_{0}^{\infty} h(t, s) x(s) d s
$$

$k \in C\left(D, R_{+}\right), D=\{(t, s) \in J \times J: t \geq s\}, h \in C\left(J \times J, R_{+}\right) .\left.\quad \Delta x\right|_{t=t_{m}}=x\left(t_{m}^{+}\right)-$ $x\left(t_{m}^{-}\right)$which denotes the jump of $x(t)$ at $t=t_{m}$. Here $x\left(t_{m}^{+}\right)$and $x\left(t_{m}^{-}\right)$represent the right- and left-sided limits of $x(t)$ at $t=t_{m}$, respectively.

Let $P C(J, E)=\{x: x$ is a map from $J$ into $E$ such that $x(t)$ is continuous at $t \neq t_{m}$ and left continuous at $t=t_{m}$ and $x\left(t_{m}^{+}\right)$exists for $m=1,2,3, \ldots$, $B P C(J, E)=\left\{x \in P C(J, E): \sup _{t \in J}\|x(t)\|<\infty\right\}$ and $T P C(J, E)=\{x \in P C(J, E):$ $x(\infty)=\lim _{t \rightarrow \infty} x(t)$ exists $\}$. Evidently, $T P C(J, E) \subset B P C(J, E)$, and $B P C(J, E)$ is a Banach space with norm $\|x\|_{B}=\sup _{t \in J}\|x(t)\|$. Let $B P C(J, P)=\{x \in B P C(J, E)$ : $x(t) \geq \theta$ for $t \in J\}, T P C(J, P)=\{x \in T P C(J, E): x(t) \geq \theta$ for $t \in J\}$ and $J^{\prime}=$ $J \backslash\left\{t_{1}, \ldots, t_{m}, \ldots\right\}$. A map $x \in T P C(J, P) \cap C^{1}\left(J^{\prime}, E\right)$ is called a non-negative solution of TVP(1) if it satisfies (1).

\section{Main Results}

Let us list some conditions.

$$
\begin{array}{r}
\left(H_{1}\right) k^{*}=\sup _{t \in J} \int_{0}^{t} k(t, s) d s<\infty, h^{*}=\sup _{t \in J} \int_{0}^{\infty} h(t, s) d s<\infty \text { and } \\
\lim _{t^{\prime} \rightarrow t} \int_{0}^{\infty}\left|h\left(t^{\prime}, s\right)-h(t, s)\right| d s=0, \quad t \in J .
\end{array}
$$

$\left(H_{2}\right)\|f(t, x, y, z)\| \leq p(t)+q(t)(a\|x\|+b\|y\|+c\|z\|), t \in J, x, y, z, \in P$, and

$$
\left\|I_{m}(x)\right\| \leq a_{m}+b_{m}\|x\|, x \in P(m=1,2,3, \ldots)
$$

where $p, q \in C\left(J, R_{+}\right)$and $a \geq 0, \quad b \geq 0, \quad a_{m} \geq 0, \quad b_{m} \geq 0 \quad(m=1,2,3, \ldots)$ satisfying

$$
p^{*}=\int_{0}^{\infty} p(t) d t<\infty, q^{*}=\int_{0}^{\infty} q(t) d t<\infty, a^{*}=\sum_{m=1}^{\infty} a_{m}<\infty, b^{*}=\sum_{m=1}^{\infty} b_{m}<\infty
$$

$\left(H_{3}\right) f(t, x, y, z)$ is nonincreasing in $x, y, z \in P$ and $I_{m}(x)$ is nonincreasing in $x \in P$ $(m=1,2,3, \ldots)$, i.e. 


$$
f(t, x, y, z) \leq f(t, \bar{x}, \bar{y}, \bar{z}), \quad t \in J, x \geq \bar{x} \geq \theta, y \geq \bar{y} \geq \theta, z \geq \bar{z} \geq \theta
$$

and

$$
I_{m}(x) \leq I_{m}(\bar{x}), \quad x \geq \bar{x} \geq \theta \quad(m=1,2,3, \ldots) .
$$

It is easy to see that when $\left(H_{1}\right)$ is satisfied, $T$ and $S$, defined by $(2)$, are bounded linear operators from $B P C(J, E)$ into $B P C(J, E)$.

Lemma 1: If conditions $\left(H_{1}\right)$ and $\left(H_{2}\right)$ are satisfied, then for any $x \in$ $B P C(J, P)$, the integral

and the series

$$
\int_{0}^{\infty} f(t, x(t),(T x)(t),(S x)(t)) d t
$$

$$
\sum_{m=1}^{\infty} I_{m}\left(x\left(t_{m}\right)\right)
$$

are convergent.

Proof: Let $x \in B P C(J, P)$. By virtue of $\left(H_{1}\right)$ and $\left(H_{2}\right)$, it is easy to see that

$$
\begin{gathered}
\int_{0}^{\infty}\|f(s, x(s),(T x)(s),(S x)(s))\| d s \\
\leq \int_{0}^{\infty} p(s) d s+\left(a+b k^{*}+c h^{*}\right)\|x\|_{B} \int_{0}^{\infty} q(s) d s<\infty \\
\sum_{m=1}^{\infty}\left\|I_{m}\left(x\left(t_{m}\right)\right)\right\| \leq \sum_{m=1}^{\infty} a_{m}+\|x\|_{B} \sum_{m=1}^{\infty} b_{m}<\infty,
\end{gathered}
$$

and

so, integral (3) and series (4) are convergent.

Lemma 2: Let conditions $\left(H_{1}\right)$ and $\left(H_{2}\right)$ be satisfied. Then $x \in T P C(J, P) \cap C^{1}\left(J^{\prime}, E\right)$ is a solution of $T V P(1)$ if and only if $x \in B P C(J, P)$ is a solution to the following impulsive integral equation

$$
x(t)=x^{*}-\int_{t}^{\infty} f(s, x(s),(T x)(s),(S x)(s)) d s-\sum_{t \leq t_{m}<\infty} I_{m}\left(x\left(t_{m}\right)\right), \quad t \in J .
$$

Proof: Let $x \in T P C(J, P) \cap C^{1}\left(J^{\prime}, E\right)$ be a solution of TVP(1). We first establish the following formula:

$$
x(t)=x(0)+\int_{0}^{t} x^{\prime}(s) d s+\sum_{0<t_{m}<t}\left[x\left(t_{m}^{+}\right)-x\left(t_{m}\right)\right], \quad t \in J .
$$

In fact, let $t_{m} \leq t \leq t_{m+1}$. Then

$$
\begin{gathered}
x\left(t_{1}\right)-x(0)=\int_{0}^{t_{1}} x^{\prime}(x) d s, \quad x\left(t_{2}\right)-x\left(t_{1}^{+}\right)=\int_{t_{1}}^{t_{2}} x^{\prime}(s) d s, \\
\ldots \ldots \ldots \ldots \ldots \ldots \ldots \ldots \ldots \ldots \ldots \ldots \ldots \ldots \ldots \ldots \\
x\left(t_{m}\right)-x\left(t_{m-1}^{+}\right)=\int_{t_{m-1}}^{t_{m}} x^{\prime}(s) d s, \quad x(t)-x\left(t_{m}^{+}\right)=\int_{t_{m}}^{t} x^{\prime}(s) d s .
\end{gathered}
$$


Summing up these equations, we get

$$
x(t)-x(0)-\sum_{i=1}^{m}\left[x\left(t_{i}^{+}\right)-x\left(t_{i}\right)\right]=\int_{0}^{t} x^{\prime}(s) d s
$$

(i.e., (6) holds). Substituting (1) into (6), we obtain

$$
x(t)=x(0)+\int_{0}^{t} f(s, x(s),(T x)(s),(S x)(s)) d s+\sum_{0<t_{m}<t} I_{m}\left(x\left(t_{m}\right)\right), \quad t \in J .
$$

By Lemma 1, integral (3) and series (4) are convergent, hence, from (1) and (7) we get

$$
x^{*}=x(0)+\int_{0}^{\infty} f(s, x(s),(T x)(s),(S x)(s)) d s+\sum_{m=1}^{\infty} I_{m}\left(x\left(t_{m}\right)\right) .
$$

Solving $x(0)$ from (8) and substituting it into (7), we find that $x(t)$ satisfies equation (5).

Conversely, if $x \in B P C(J, P)$ is a solution of equation (5), direct differentiation of (5) implies that $x \in C^{1}\left(J^{\prime}, E\right)$ and $x(t)$ satisfies $\operatorname{TVP}(1)$.

Consider operator $A$ defined by

$$
(A x)(t)=x^{*}-\int_{t}^{\infty} f(s, x(s),(T x)(s),(S x)(s)) d s-\sum_{t \leq t_{m}<\infty} I_{m}\left(x\left(t_{m}\right)\right) .
$$

Lemma 3: If conditions $\left(H_{1}\right)$ and $\left(H_{2}\right)$ are satisfied, then $A$ defined by $(9)$ is an operator from $B P C(J, P)$ into $B P C(J, P)$.

Proof: Let $x \in B P C(J, P)$. Since $f \in C(J \times P \times P \times P,-P), I_{m} \in C(P,-P)$ and $x^{*} \in P$, we see that $(A x)(t) \geq \theta$ for $t \in J$, and clearly $A x \in P C(J, P)$. By $\left(H_{1}\right)$ and $\left(H_{2}\right)$, we have

$$
\begin{gathered}
\|(A x)(t)\| \leq\left\|x^{*}\right\|+\int_{t}^{\infty} p(s) d s+\left(a+b k^{*}+c h^{*}\right)\|x\|_{B} \int_{t}^{\infty} q(s) d s \\
\quad+\sum_{t \leq t_{m} \leq \infty} a_{m}+\|x\|_{\substack{B \\
t_{m}<\infty}} b_{m} \\
\leq\left\|x^{*}\right\|+p^{*}+a^{*}+\left[b^{*}+\left(a+b k^{*}+c h^{*}\right) q^{*}\right]\|x\|_{B}, \quad t \in J,
\end{gathered}
$$

and therefore

$$
\|A x\|_{B} \leq\left\|x^{*}\right\|+p^{*}+a^{*}+\left[b^{*}+\left(a+b k^{*}+c h^{*}\right) q^{*}\right]\|x\|_{B} .
$$

Hence $A x \in B P C(J, P)$.

In the following, let $J_{0}=\left[0, t_{1}\right], J_{m}=\left(t_{m}, t_{m+1}\right](m=1,2,3, \ldots)$.

Theorem 1: Let cone $P$ be fully regular and conditions $\left(H_{1}\right),\left(H_{2}\right),\left(H_{3}\right)$ be satisfied. Assume that

$$
r=b^{*}+\left(a+b k^{*}+c h^{*}\right) q^{*}<1,
$$

where constants $k^{*}, h^{*}, a, b, c, q^{*}, b^{*}$ are defined by $\left(H_{1}\right)$ and $\left(H_{2}\right)$. There exists a nondecreasing sequence $\left\{x_{n}\right\} \subset T P C(J, P) \cap C^{1}\left(J^{\prime}, E\right)$ which converges on $J$ (uniformly in each $\left.J_{m}, m=0,1,2, \ldots\right)$ to the minimal solution $\bar{x} \in \operatorname{TPC}(J, P) \cap$ $C^{1}\left(J^{\prime}, E\right)$ of $T V P(1)$ in $T P C(J, P) \cap C^{1}\left(J^{\prime}, E\right)$, i.e., for any solution $x \in$ 
$T P C(J, P) \cap C^{1}\left(J^{\prime}, E\right)$ of $T V P(1)$, we have

Moreover,

$$
x(t) \geq \bar{x}(t), \quad t \in J
$$

and

$$
\bar{x}(t) \geq \bar{x}\left(t^{\prime}\right) \geq x^{*}, \quad 0 \leq t<t^{\prime}<\infty,
$$

$$
\|\bar{x}\|_{B} \leq(1-r)^{-1}\left(\left\|x^{*}\right\|+p^{*}+a^{*}\right),
$$

where $r$ is given by (11) and $p^{*}, a^{*}$ are defined by $\left(H_{2}\right)$.

Proof: Let $x_{0}(t)=\theta, x_{n}(t)=\left(A x_{n-1}\right)(t) \quad(n=1,2,3, \ldots)$, i.e.,

$$
\begin{aligned}
& x_{n}(t)=x^{*}-\int_{t}^{\infty} f\left(s, x_{n-1}(s),\left(T x_{n-1}\right)(s),\left(S x_{n-1}\right)(s)\right) d s \\
&-\sum_{t} \leq t_{m}<\infty \\
& I_{m}\left(x_{n-1}\left(t_{m}\right)\right), \quad t \in J(n=1,2,3, \ldots) .
\end{aligned}
$$

By Lemma $3, x_{n} \in B P C(J, P)(n=0,1,2, \ldots)$ and $x_{1}(t) \geq \theta=x_{0}(t)$ for $t \in J$, so, (15) and $\left(\mathrm{H}_{3}\right)$ imply that

$$
\theta=x_{0}(t) \leq x_{1}(t) \leq x_{2}(t) \leq \ldots \leq x_{n}(t) \leq \ldots, t \in J .
$$

On the other hand, from (10) we know

$$
\left\|x_{n}\right\|_{B}=\left\|A x_{n-1}\right\|_{B} \leq d+r\left\|x_{n-1}\right\|_{B}, \quad(n=1,2,3, \ldots)
$$

where $d=\left\|x^{*}\right\|+p^{*}+a^{*}$ and $r$ is given by (11), thus

$$
\begin{gathered}
\left\|x_{n}\right\|_{B} \leq d+r\left(d+r\left\|x_{n-2}\right\|_{B}\right) \leq d+r d+r^{2}\left(d+r\left\|x_{n-3}\right\|_{B}\right) \\
\leq d+r d+\ldots+r^{n-1} d+r^{n}\left\|x_{0}\right\|_{B}=d+r d+\ldots+r^{n-1} d=d\left(1-r^{n}\right)(1-r)^{-1} \\
\leq d(1-r)^{-1}, \quad(n=1,2,3, \ldots) .
\end{gathered}
$$

It follows from (16), (17), and the full regularity of $P$ that the following limit exists:

$$
\lim _{n \rightarrow \infty} x_{n}(t)=\bar{x}(t), \quad t \in J .
$$

Now we have, by (17),

$$
\begin{gathered}
\left\|f\left(s, x_{n-1}(s),\left(T x_{n-1}\right)(s),\left(S x_{n-1}\right)(s)\right)\right\| \\
\leq p(s)+\left(a+b k^{*}+c h^{*}\right)\left\|x_{n-1}\right\|_{B} q(s) \\
\leq p(s)+\left(a+b k^{*}+c h^{*}\right) d(1-r)^{-1} q(s), \quad s \in J \quad(n=1,2,3, \ldots),
\end{gathered}
$$

so, from $(15)$ we know that functions $\left\{x_{m n}(t)\right\} \quad(n=0,1,2, \ldots)$ are equicontinuous in $\bar{J}_{m}(m=0,1,2, \ldots)$, where $\bar{J}_{m}=\left[t_{m}, t_{m+1}\right]$ and

$$
x_{m n}(t)=\left\{\begin{array}{cc}
x_{n}(t), & t_{m}<t \leq t_{m+1} \\
x_{n}\left(t_{m}^{+}\right), & t=t_{m} .
\end{array}\right.
$$

Hence, observing (18) and using the Ascoli-Arzela theorem, we see that $\left\{x_{m n}(t)\right\}$ $(n=0,1,2, \ldots)$ is compact in $C\left(\bar{J}_{m}, E\right) \quad(m=0,1,2, \ldots)$. and therefore, by diagonal method, $\left\{x_{n}(t)\right\}$ has a subsequence which converges to $\bar{x}(t)$ uniformly in each $J_{m}$ $(m=0,1,2, \ldots)$. Since $P$ is also normal and $\left\{x_{n}(t)\right\}$ is nondecreaisng, on account of (16), we conclude that the entire sequence $\left\{x_{n}(t)\right\}$ converges to $\bar{x}(t)$ uniformly in 
each $J_{m}(m=0,1,2, \ldots)$, hence, $\bar{x} \in P C(J, P)$. Moreover, from (17) we know that $\bar{x} \in B P C(J, P)$ and $\|\bar{x}\|_{B} \leq d(1-r)^{-1}$, i.e., (14) holds.

From (18). and (19), we see that

$$
\begin{gathered}
f\left(s, x_{n-1}(s),\left(T x_{n-1}\right)(s),\left(S x_{n-1}\right)(s)\right) \rightarrow f(s, \bar{x}(s),(T \bar{x})(s),(S \bar{x})(s)) \\
\text { as } n \rightarrow \infty, s \in J
\end{gathered}
$$

and

$$
\begin{aligned}
& \left\|f\left(s, x_{n-1}(s),\left(T x_{n-1}\right)(s),\left(S x_{n-1}\right)(s)\right)-f(s, \bar{x}(s),(T \bar{x})(s),(S \bar{x})(s))\right\| \\
& \leq 2 p(s)+2\left(a+b k^{*}+c h^{*}\right) d(1-r)^{-1} q(s), \quad s \in J \quad(n=1,2,3, \ldots) .
\end{aligned}
$$

In addition, (17), (18) and $\left(H_{2}\right)$ imply that

and

$$
I_{m}\left(x_{n-1}\left(t_{m}\right)\right) \rightarrow I_{m}\left(\bar{x}\left(t_{m}\right)\right) \text { as } n \rightarrow \infty(m=1,2,3, \ldots)
$$

$$
\begin{gathered}
\sum_{m=j}^{\infty}\left\|I_{m}\left(x_{n-1}\left(t_{m}\right)\right)\right\| \leq \sum_{m=j}^{\infty} a_{m}+d(1-r)^{-1} \sum_{m=j}^{\infty} b_{m} \quad(n=1,2,3, \ldots), \\
\sum_{m=j}^{\infty}\left\|I_{m}\left(\bar{x}\left(t_{m}\right)\right)\right\| \leq \sum_{m=j}^{\infty} a_{m}+d(1-r)^{-1} \sum_{m=j}^{\infty} b_{m} .
\end{gathered}
$$

Observing (20)-(24) and taking limits in (15) as $n \rightarrow \infty$, we obtain by virtue of the dominated convergence theorem that

$$
\bar{x}(t)=x^{*}-\int_{t}^{\infty} f(s, \bar{x}(s),(T \bar{x})(s),(S \bar{x})(s)) d s-\sum_{t \leq t_{m}<\infty} I_{m}\left(\bar{x}\left(t_{m}\right)\right), \quad t \in J,
$$

which by Lemma 2 implies that $\bar{x} \in T P C(J, P) \cap C^{1}\left(J^{\prime}, E\right)$ and $\bar{x}(t)$ is a solution of TVP(1). From (25) we see clearly that (13) holds.

Finally, we prove the minimal property of $\bar{x}(t)$. Let $x \in T P C(J, P) \cap C^{1}\left(J^{\prime}, E\right)$ by any solution of TVP(1). By Lemma 2, $x(t)$ satisfies equation (5). We have $x(t) \geq \theta=x_{0}(t)$ for $t \in J$. Assume that $x(t) \geq x_{n-1}(t)$ for $t \in J$. Then (15), (5) and $\left(H_{3}\right)$ imply that $x(t) \geq x_{n}(t)$ for $t \in J$. Hence, by induction, $x(t) \geq x_{n}(t)$ for $t \in J(n=0,1,2, \ldots)$, and by taking the limit, we get $x(t) \geq \bar{x}(t)$ for $t \in \bar{J}$, i.e., (12) holds. The proof is complete.

Example 1: Consider the TVP of infinite system for scalar nonlinear impulsive integro-differential equations

$$
\left\{\begin{array}{c}
x_{n}^{\prime}=-\frac{e^{-t}}{2^{n+3}}\left(1+x_{n}+\sqrt{x_{n+1}+2 x_{2 n+1}}\right)-\frac{e^{-2 t}}{3^{n}}\left(\int_{0}^{t} e^{-(t+1) s} x_{n}(s) d s\right)^{1 / 3} \\
-\frac{e^{-t}}{4^{n}}\left(\int_{0}^{\infty} \frac{x_{2 n}(s) d s}{1+t+s^{2}}\right)^{1 / 5}, \quad 0 \leq t<\infty, \quad t \neq m \\
\left.\Delta x_{n}\right|_{t=m}=-\frac{1}{2^{n+m+2}}\left[x_{n}(m)+x_{n+2}(m)\right], \quad(m=1,2,3, \ldots) \\
x_{n}(\infty)=\frac{1}{n^{2}}, \quad(n=1,2,3, \ldots) .
\end{array}\right.
$$

Corollary: $T V P(26)$ has a minimal, nonnegative and continuously differentiable on $[0, \infty) \backslash\{1,2,3, \ldots\}$ solution $\left\{x_{n}(t)\right\} \quad(n=1,2,3, \ldots)$ satisfying 


$$
\sup _{0 \leq t<\infty} \sum_{n=1}^{\infty} x_{n}(t)<\infty .
$$

Proof: Let $E=\ell^{1}=\left\{x=\left(x_{1}, \ldots, x_{n}, \ldots\right): \sum_{n=1}^{\infty}\left|x_{n}\right|<\infty\right]$ with norm $\|x\|=$ $\sum_{n=1}^{\infty}\left|x_{n}\right|$ and $P=\left\{x=\left(x_{1}, \ldots, x_{n}, \ldots\right) \in \ell^{1}: x_{n} \geq 0, \quad n=1,2,3, \ldots\right\}$. Thus, $P$ is a normal cone in $E$. Since $\ell^{1}$ is weakly complete, we conclude that $P$ is regular. We now prove that $P$ is fully regular. Let $x_{k}=\left(x_{k 1}, \ldots, x_{k n}, \ldots\right) \in \ell^{1} \quad(k=1,2,3, \ldots)$ satisfy $x_{1} \leq x_{2} \leq \ldots \leq x_{k} \leq \ldots$ and $M=\sup _{k}\left\|x_{k}\right\|<\infty$. Then, $x_{1 n} \leq x_{2 n} \leq \ldots \leq$ $x_{k n} \leq \ldots \leq M \quad(n=1,2,3, \ldots)$, so, $\lim _{k \rightarrow \infty} x_{k n}=y_{n} \quad(n=1,2,3, \ldots)$ exist. For any positive integer $i$, we have $\sum_{n=1}^{i}\left|x_{k n}\right| \leq M(k=1,2,3, \ldots)$, so, by letting $k \rightarrow \infty$, we find $\sum_{n=1}^{i}\left|y_{n}\right| \leq M$. Since $i$ is arbitrary, it follows that $\sum_{n=1}^{\infty}\left|y_{n}\right| \leq M<\infty$, and therefore $y=\left(y_{1}, \ldots y_{n}, \ldots\right) \in \ell^{1}$. It is clear that $x_{1} \leq x_{2} \leq \ldots \leq x_{k} \leq \ldots \leq y$, consequently, the regularity of $P$ implies that $\left\|x_{k}-x\right\| \rightarrow 0$ as $k \rightarrow \infty$ for some $x \in \ell^{1}$. Hence the full regularity of $P$ is proven.

Now, system (26) can be regarded as a TVP of the form (1), where $k(t, s)=$ $e^{-(t+1) s}, \quad h(t, s)=\left(1+t+s^{2}\right)^{-1}, \quad x=\left(x_{1}, \ldots, x_{n}, \ldots\right), \quad y=\left(y_{1}, \ldots, y_{n}, \ldots\right), \quad z=$ $\left(z_{1}, \ldots, z_{n}, \ldots\right), f=\left(f_{1}, \ldots, f_{n}, \ldots\right)$, in which

$$
f_{n}(t, x, y, z)=-\frac{e^{-t}}{2^{n+3}}\left(1+x_{n}+\sqrt{\left.x_{n+1}+2 x_{2 n+1}\right)}-\frac{e^{-2 t}}{3^{n}} y_{n}^{1 / 3}-\frac{e^{-t}}{4^{n}} z_{2 n}^{1 / 5},\right.
$$

and $t_{m}=m, I_{m}=\left(I_{m 1}, \ldots, I_{m n}, \ldots\right)$ with

$$
I_{m n}(x)=-\frac{1}{2^{n+m+2}}\left(x_{n}+x_{n+2}\right), \quad(m, n=1,2,3, \ldots)
$$

and $x^{*}=\left(1, \ldots, \frac{1}{n^{2}}, \ldots\right) \in P . \quad$ Evidently, $f \in C(J \times P \times P \times P,-P)$ and $I_{m} \in$ $C(P,-P)(m=1,2,3, \ldots) .\left(H_{1}\right)$ is obviously satisfied since

$$
\begin{gathered}
k^{*}=\sup _{t \in J} \int_{0}^{t} e^{-(t+1) s} d s=\sup _{t \in J} \frac{1}{t+1}\left(1-e^{-(t+1) t}\right) \leq 1, \\
h^{*}=\sup _{t \in J} \int_{0}^{\infty} \frac{d s}{1+t+s^{2}} \leq \int_{0}^{\infty} \frac{d s}{1+s^{2}}=\frac{\pi}{2}
\end{gathered}
$$

and

$$
\int_{0}^{\infty}\left|\frac{1}{1+t^{\prime}+s^{2}}-\frac{1}{1+t+s^{2}}\right| d s=\int_{0}^{\infty} \frac{\left|t^{\prime}-t\right|}{\left(1+t^{\prime}+s^{2}\right)\left(1+t+s^{2}\right)} d s \leq \frac{\pi}{2}\left|t^{\prime}-t\right| \rightarrow 0
$$

as $t^{\prime} \rightarrow t$. It is easy to verify the following scalar inequality:

so, for $t \in J, x, y, z \in P$,

$$
u^{\alpha} \leq 1-\alpha+\alpha u, \quad 0 \leq u<\infty, 0<\alpha<1,
$$

$$
\left|f_{n}(t, x, y, z)\right|
$$




$$
\begin{gathered}
\leq \frac{e^{-t}}{2^{n+3}}\left(1+x_{n}+\frac{1}{2}\left(x_{n+1}+2 x_{2 n+1}\right)\right)+\frac{e^{-2 t}}{3^{n}}\left(\frac{2}{3}+\frac{1}{3} y_{n}\right)+\frac{e^{-t}}{4^{n}}\left(\frac{4}{5}+\frac{1}{5} z_{2 n}\right) \\
\leq \frac{e^{-t}}{2^{n+3}}(1+\|x\|)+\frac{e^{-2 t}}{3^{n}}\left(\frac{2}{3}+\frac{1}{3}\|y\|\right)+\frac{e^{-t}}{4^{n}}\left(\frac{4}{5}+\frac{1}{5}\|z\|\right)
\end{gathered}
$$

and therefore,

$$
\begin{aligned}
\|f(t, x, y, z)\| & =\sum_{n=1}^{\infty}\left|f_{n}(t, x, y, z)\right| \leq e^{-t}\left(\sum_{n=1}^{\infty} \frac{1}{2^{n+3}}+\frac{2}{3} \sum_{n=1}^{\infty} \frac{1}{3^{n}}+\frac{4}{5} \sum_{n=1}^{\infty} \frac{1}{4^{n}}\right) \\
+e^{-t} & \left(\|x\| \sum_{n=1}^{\infty} \frac{1}{2^{n+3}}+\frac{1}{3}\|y\| \sum_{n=1}^{\infty} \frac{1}{3^{n}}+\frac{1}{5}\|z\| \sum_{n=1}^{\infty} \frac{1}{4^{n}}\right) \\
& =\frac{87}{120} e^{-t}+e^{-t}\left(\frac{1}{8}\|x\|+\frac{1}{6}\|y\|+\frac{1}{15}\|z\|\right) .
\end{aligned}
$$

In addition, we have, for $x \in P$,

and so

$$
\left|I_{m n}(x)\right| \leq \frac{1}{2^{n+m+1}}\|x\|
$$

$$
\left\|I_{m}(x)\right\|=\sum_{n=1}^{\infty}\left|I_{m n}(x)\right| \leq \frac{1}{2^{m+1}}\|x\| \text {. }
$$

Hence $\left(H_{2}\right)$ is satisfied for $p(t)=(87 / 120) e^{-t}, q(t)=e^{-t}, \quad a=1 / 8, \quad b=1 / 6$, $c=1 / 15, \quad a_{m}=0$ and $b_{m}=1 / 2^{m+1}(m=1,2,3, \ldots)$, and therefore $p^{*}=87 / 120$, $q^{*}=1, a^{*}=0$ and $b^{*}=1 / 2$.

On the other hand, $\left(\mathrm{H}_{3}\right)$ is obviously satisfied, and

$$
r=b^{*}+\left(a+b k^{*}+c h^{*}\right) q^{*} \leq \frac{1}{2}+\left(\frac{1}{8}+\frac{1}{6}+\frac{\pi}{30}\right)<1,
$$

i.e., (11) holds. Hence the assertion follows from Theorem 1.

\section{References}

[1] Du, Y., Fixed points of increasing operators in ordered Banach spaces and applications, Appl. Anal. 38 (1990), 1-20.

[2] Guo, D. and Lakshmikantham, V., Nonlinear Problems in Abstract Cones, Academic Press, New York 1988.

[3] Lakshmikantham, V., Bainov, D.D. and Simeonov, P.S., Theory of Impulsive Differential Equations, World Scientific, Singapore 1989. 


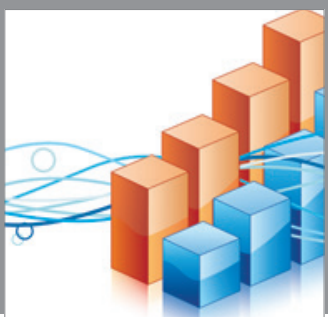

Advances in

Operations Research

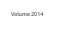

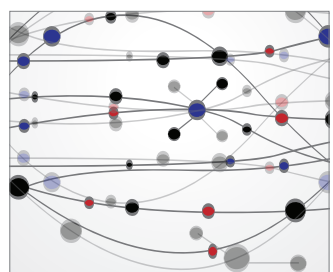

\section{The Scientific} World Journal
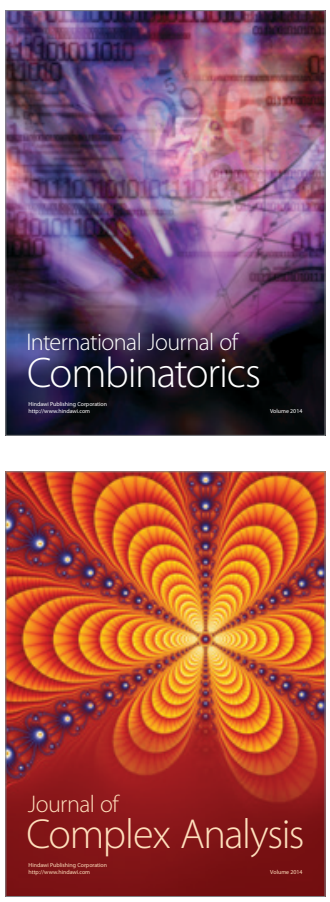

International Journal of

Mathematics and

Mathematical

Sciences
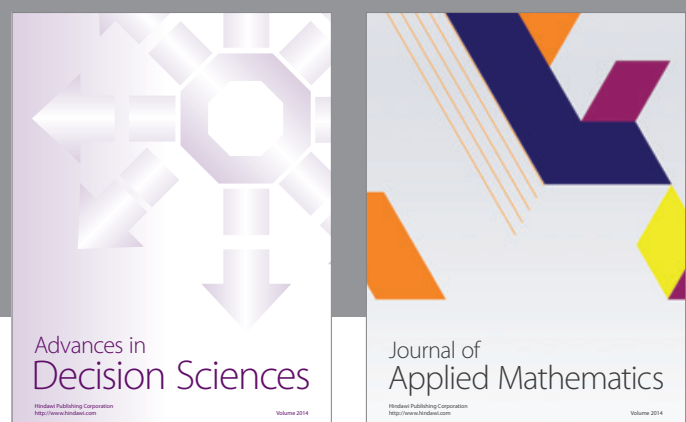

Journal of

Applied Mathematics
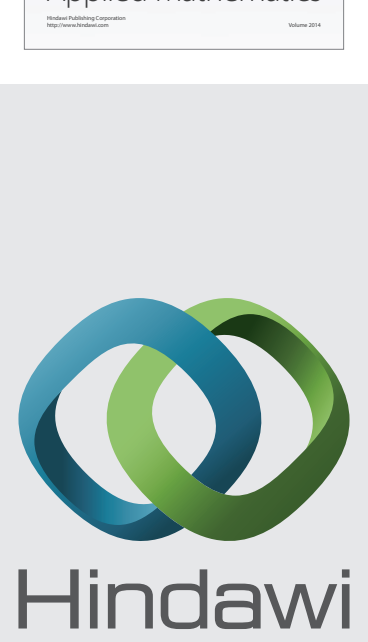

Submit your manuscripts at http://www.hindawi.com
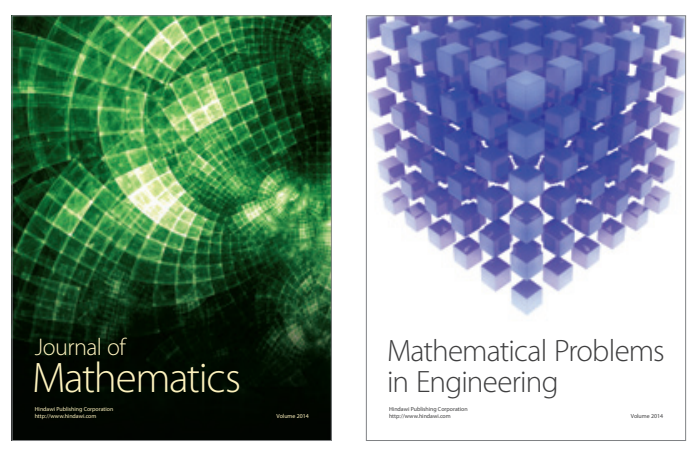

Mathematical Problems in Engineering
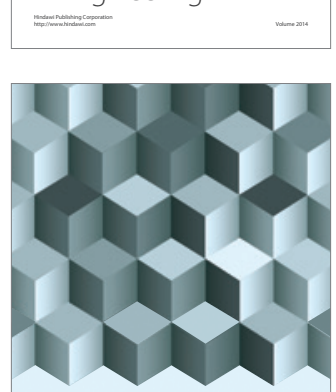

Journal of

Function Spaces
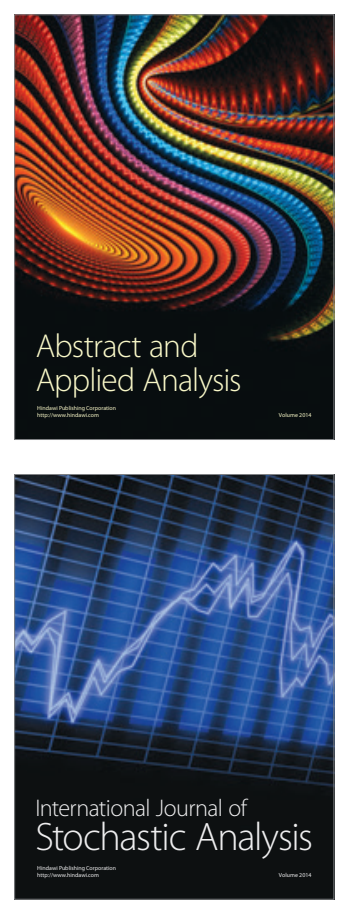

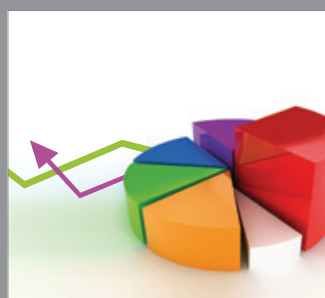

ournal of

Probability and Statistics

Promensencen
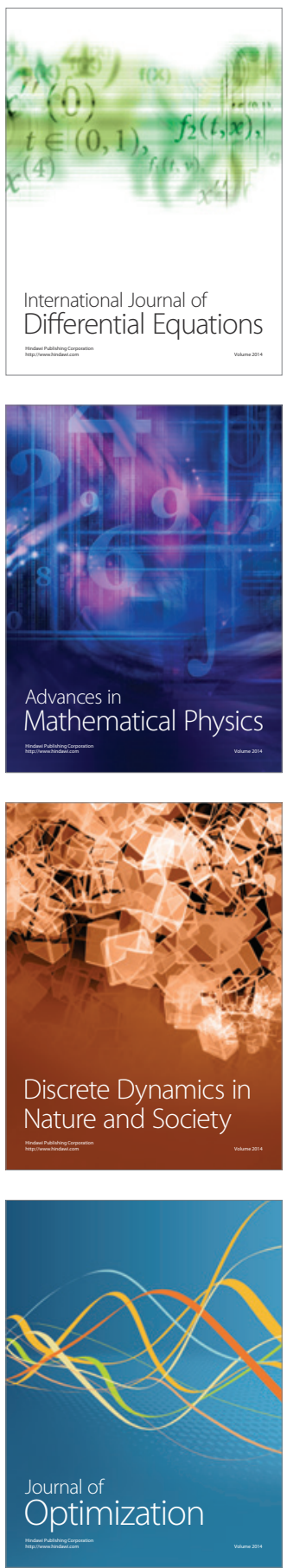